\title{
Evaluation of the Rupture Test for Stability Studies of Soft-Shell Capsules
}

\author{
Ghada Bachour*, Nadia Araci Bou-Chacra, and Raimar Löbenberg \\ University of Alberta, Edmonton, Canada
}

e-mail: bachour@ualberta.ca

\section{ABSTRACT}

The United States Pharmacopoeia (USP) implemented a rupture test in General Chapter $<2040>$ for the evaluation of soft-shell capsules. It was first published in USP 30-NF 25 in 2007. Nutraceutical manufacturers showed in the past that the rupture test does not work for some of their soft-shell capsule products if a long-term stability test was performed. The present study aimed to evaluate the rupture test as a quality control tool for long-term stability samples using different enzymes, which were introduced in USP 39 for tier-two dissolution testing, and apply it to the rupture test.

Commercial hydrophobic, oil-based, oral multivitamin soft-shell capsules were tested using the rupture test according to USP General Chapter <2040>. The same product was tested after 18 months exposure to long-term stability conditions. The stability samples were also tested using immersion media containing pepsin, pancreatin, papain, and bromelain.

The commercial product passed the rupture test. The long-term stability samples failed the rupture test in all media including the enzyme-containing medium described for Tier 2 testing.

The current study shows that the rupture test is sensitive and can detect gelatin cross-linking in long-term stability samples. From dissolution studies, it is known that in vitro quality control tests might over-discriminate and have limited impact on the in vivo status. Industry needs to develop alternative methods and generate scientific data to demonstrate product performance when long-term stability samples fail the rupture test.

KEYWORDS: Rupture test; USP <2040>; cross-linking; dissolution.

\section{INTRODUCTION}

isintegration testing is used routinely for dietary supplements $(1,2)$. The rupture test for soft-shell capsules was first introduced in USP General Chapter <2040> and published in USP 30-NF 25 in 2007. The rupture test is a quality control test for soft-shell capsules that is used instead of the disintegration test described in USP General Chapter <701>.

General Chapter <2040> states (3), "Disintegration and dissolution tests as described in this chapter are quality-control tools to assess performance characteristics of dietary supplement finished dosage forms. These performance standards are intended to detect problems that may arise due to use or misuse, or changes in coatings, lubricants, disintegrants, and other components. These performance tests are also intended to detect manufacturing process issues such as over-compression and over-drying that would affect the release characteristics of the final dosage forms."
Disintegration or rupture tests are also used in dosage form development. General Chapter <1151> states (4), "Drug product stability involves the evaluation of chemical stability, physical stability, and performance over time. The chemical stability of the drug substance in the dosage form matrix must support the expiration dating... For tablets, capsules, oral suspensions, and implants, in vitro release test procedures such as dissolution and disintegration provide a measure of continuing consistency in performance over time."

However, it is important to point out that the USP does not mention the use of a rupture test for stability samples. This is different from dissolution testing. General Chapter $<711>$ states (5), "Gelatin, in the presence of certain compounds and/or in certain storage conditions, including but not restricted to high humidity and temperature, may present cross-linking. A pellicle may form on the external and/or internal surface of the gelatin capsule shell or on the dosage form that prevents the drug from being released during dissolution testing."

* Corresponding author. 
General Chapter <1094> gives some more details about the problem stability conditions can cause (6): "Crosslinking can be caused by agents present in the capsule fill that react with gelatin molecules, resulting in the formation of a pellicle on the internal surface of the shell. Less often, a pellicle may form on the external surface of the shell arising from reactive agents present in, or derived from the intermediate of final packaging components. A pellicle is a thin, water insoluble clear membrane of cross-linked protein on the inner or outer surface of the capsule that prevents the capsule fill from being released. Cross-linking is evidenced by the observation of a thin membrane or a gelatinous mass during dissolution testing because the pellicle itself may be difficult to observe."

The nutraceutical industry reported problems using the rupture test for soft-shell capsules after exposing them to stability conditions. The stability samples did not passes General Chapter <2040> requirements. The aim of this study was to investigate if the enzymes listed in General Chapter $<711>$ for Tier 2 dissolution testing procedures can be used to overcome the observed failure of the rupture test after soft-shell capsules were exposed to long-term stability conditions.

\section{MATERIALS}

PreserVision Eye Vitamin capsules (lot \#6245K0566) and a stability sample (lot \#34033FN566-180) were provided by Bausch and Lomb. The latter lot was exposed to long-term stability conditions of $25^{\circ} \mathrm{C}, 65 \% \mathrm{RH}$ for 18 months. Pepsin with an activity $\geq 250$ units/mg protein was purchased from Sigma-Aldrich (lot SLBL1721V). Pancreatin with an activity of 4,000 units/g protein (lot 897331), papain from Carica papaya with an activity of 100,000 units/g (lot 992586), and bromelain from Ananas comosus with an activity of $2400 \mathrm{GDU} / \mathrm{g}$ (lot 562170) were received from Creative Enzymes.

\section{Methods}

The rupture test was performed according to General Chapter <2040> (3). Six soft-shell capsules were tested directly in $500 \mathrm{~mL}$ of degassed purified water (1). The test was performed at $37 \pm 0.5{ }^{\circ} \mathrm{C}$ at $50 \mathrm{rpm}$ using USP Apparatus 2 (Varian model 7020, Agilent). The capsules were observed, and the time of shell rupture was recorded. The rupture test was continued until all samples had ruptured or was aborted at $30 \mathrm{~min}$.

Enzyme media were prepared according to USP 39-NF 34 General Chapter <1094> (6).

The rupture test was repeated using the following media: simulated gastric fluid TS with enzyme (pepsin); simulated intestinal fluid TS with enzyme (pancreatin), pH 4.5 buffer USP with papain, and $\mathrm{pH} 4.5$ buffer USP with bromelain. The rupture test was performed for $60 \mathrm{~min}$, and the shell rupture times were recorded.

\section{RESULTS}

The results of the rupture test of the commercial product and the stability sample are listed in Table 1 . According General Chapter $\langle 2040\rangle$, the requirements are met if all of the capsules tested rupture in not more than $15 \mathrm{~min}$. If 1 or 2 of the capsules rupture in more than 15 but not more than $30 \mathrm{~min}$, the test is repeated on 12 additional capsules.

As seen, all six capsules of the commercial product passed the rupture test (Figure 1), but all soft-shell capsules exposed to long-term stability conditions failed the rupture test. Figure 2 shows hydration of the capsule shell and swelling but no rupturing of the soft-shell capsules. A gelatinous mass was formed, and no release of the contents was observed. If gelatin capsules fail the test in water, USP offers the possibility of using enzymes (3): "For soft gelatin capsules that do not conform to the above

Table 1. Rupture Test of Commercial Soft-Shell Capsules and Stability Samples Exposed to Long-Term Stability Conditions ${ }^{a}$

\begin{tabular}{|c|c|c|c|c|}
\hline \multirow{2}{*}{ Sample No. } & \multicolumn{2}{|c|}{$\begin{array}{c}\text { Real-Time Samples } \\
\text { (commercial product) }\end{array}$} & Eong-Term Stability Samples \\
\cline { 2 - 5 } & End point time (min) & Results & $55: 40$ & Results \\
\hline 1 & $5: 30$ & Passed & $57: 06$ & Failed \\
\hline 2 & $8: 00$ & Passed & $52: 33$ & Failed \\
\hline 3 & $4: 40$ & Passed & $60: 00$ & Failed \\
\hline 4 & $4: 50$ & Passed & $55: 20$ & Failed \\
\hline 5 & $5: 20$ & Passed & $56: 08$ & Failed \\
\hline 6 & $8: 50$ & Passed & & Failed \\
\hline
\end{tabular}

${ }^{a} 25^{\circ} \mathrm{C}, 65 \%$ RH for 18 months 


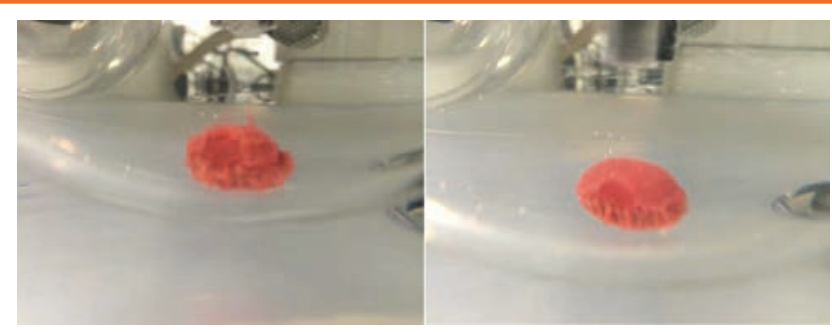

Figure 1. Image of a commercial soft-shell capsule rupturing.

rupture test acceptance criteria, repeat the test with the addition of papain to the Medium in the amount that results in an activity of not more than 550,000 Units/L of Medium or with the addition of bromelain in the amount that results in an activity of not more than 30 gelatindissolving units (GDU)/L of Medium."

\section{Rupture Test Using Enzyme Media}

USP 39 lists four enzymes that can be used for dissolution testing of gelatin-containing dosage forms that show cross-linking (5). These enzymes are pepsin, pancreatin, papain, and bromelain. USP General Chapter <2040> lists only papain or bromelain for the rupture test (3). Therefore, this study investigated pepsin and pancreatin as hydrolytic enzymes for the rupture test. The rupture test results for the long-term stability samples of soft-sell capsules using different enzyme media are listed in Table 2.

All stability samples tested failed to rupture within the specified time interval. They formed a thin, rubbery, water insoluble, clear membrane of cross-linked protein that prevented the capsule fill from being released. However, the capsules disintegrated readily when they were subjected to shear forces as they were emptied out of the vessel at the end of the test.

The study shows that the rupture test is not a suitable quality control or performance test for the particular

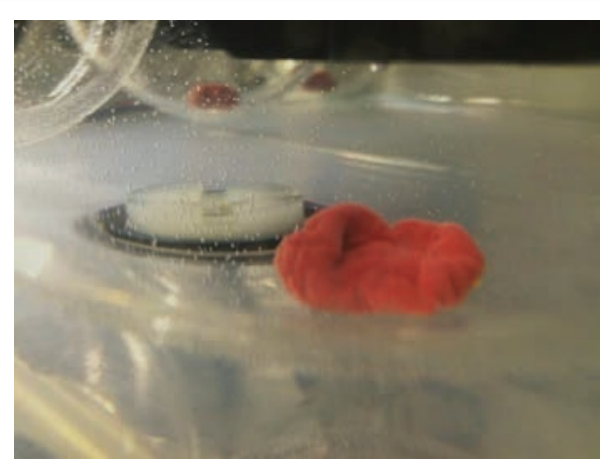

Figure 2. Image of long-term stability sample not rupturing within 30 min.

product tested after exposure to long-term stability conditions. This is in agreement with a study by Almukainzi et al. (7). That study showed that, depending on the capsule contents, the rupture test or disintegration test can be sensitive to stability studies, but this was on a case-by-case basis. As explained earlier, USP uses the disintegration test "to detect problems that may arise due to use or misuse, or changes in coatings, lubricants, disintegrants, and other components...(and to) detect manufacturing process issues such as over-compression and over-drying that would affect the release characteristics of the final dosage forms (3)."

Gelatin cross-linking is a well-known phenomenon. The current study shows that the rupture test failures were due to cross-linking, and this was detected by the rupture test. The impact of cross-linking on dissolution results is well studied. Enzymes are helpful if in vitro dissolution results change due to gelatin cross-linking $(8,9)$.

Brown et al. (10) investigated the dissolution and disintegration behavior of acetaminophen capsules. They showed differences between the in vitro dissolution behavior of stressed and unstressed capsules; however, gamma scintigraphy showed the insides of the in vivo

Table 2. Rupture Test of Commercial Soft-Shell Capsules and Stability Samples Exposed to Long-Term Stability Conditions after Addition of Digestive Enzymes

\begin{tabular}{|c|c|c|c|c|}
\hline \multirow{2}{*}{ Sample No. } & \multicolumn{4}{|c|}{$\begin{array}{c}\text { Long-Term Stability Samples } \\
\text { End Point Time (min) }\end{array}$} \\
\cline { 2 - 5 } & \begin{tabular}{c} 
Pepsin \\
\cline { 2 - 5 }
\end{tabular} & $\begin{array}{c}\text { Pancreatin } \\
\text { Act. NMT 2000 units/L }\end{array}$ & $\begin{array}{c}\text { Papain } \\
\text { Act. NMT 550,000 unites/L }\end{array}$ & $\begin{array}{c}\text { Bromelain } \\
\text { Act. NMT 30 GDU/L }\end{array}$ \\
\hline 1 & 28.13 & 48.07 & 39.20 & 48.09 \\
\hline 2 & 29.30 & 46.39 & 41.28 & 49.19 \\
\hline 3 & 28.60 & 44.31 & 40.28 & 48.66 \\
\hline 4 & 28.70 & 42.22 & 38.12 & 47.12 \\
\hline 5 & 39.50 & 47.44 & 37.57 & 47.22 \\
\hline 6 & 28.60 & 46.57 & 37.45 & 47.50 \\
\hline
\end{tabular}


disintegration behavior. They concluded that there were no differences between the in vivo disintegration properties of moderately stressed and unstressed capsules. In another study, Digenis et al. (11) reviewed the issue of cross-linking for dissolution conditions and its relevance to bioequivalence. They reported that changes due to cross-linking rarely cause bioavailability problems or bioequivalence failure. In another study (12), the authors showed that $A U C$ and $C_{\max }$ amoxicillin capsules were not affected even if there was a delayed absorption of the stressed capsules. Meyer et al. (13) reported similar results for hard and soft-gel capsules, but their study found bioequivalence for severely stressed capsules.

The current study shows that the rupture test is sensitive and can detect gelatin cross-linking in long-term stability samples. The tested stability soft-shell capsules failed the rupture test, while commercial capsules passed. From dissolution studies it is known that in vitro quality control tests might over discriminate and have limited impact on the in vivo status.

Based on our observation that the cross-linked capsules ruptured readily when emptied out of the vessel, we can conclude that they would likely rupture in the stomach, because the capsule would be impacted by the stomach and food contents and would disintegrate even if crosslinked.

Industry needs to develop alternative methods and generate scientific data to demonstrate product performance in long-term stability studies with rupture test failures.

\section{ACKNOWLEDGMENTS}

The authors would like to thank the International Institute of Education Scholar Rescue Fund, the University of Alberta International Faculty of Pharmacy and Pharmaceutical Sciences, and the Drug Development and Innovation Centre for their financial support.

\section{CONFLICT OF INTEREST}

The authors report no conflict of interest.

\section{REFERENCES}

1. Almukainzi, M.; Salehi, M.; Bou-Chacra, N. A.; Löbenberg, R. Investigation of the Performance of the Disintegration Test for Dietary Supplements. AAPS J. 2010, 12 (4), 602-607. DOI: 10.1208/s12248-010-9221-1.

2. Donauer, N.; Löbenberg, R. A. mini review of scientific and pharmacopeial requirements for the disintegration test. Int. J. Pharm. 2007, 345 (1-2), 2-8. DOI: 10.1016/j. ijpharm.2007.08.045.

3. <2040> Disintegration and Dissolution of Dietary Supplements.
In The United States Pharmacopeia and National Formulary USP 32-NF 27; The United States Pharmacopeial Convention, Inc: Rockville, MD, 2009.

4. <1151> Pharmaceutical Dosage Forms. In The United States Pharmacopeia and National Formulary USP 32-NF 27; The United States Pharmacopeial Convention, Inc: Rockville, MD, 2009.

5. <711> Dissolution. In The United States Pharmacopeia and National Formulary USP 39-NF 34 ; The United States Pharmacopeial Convention, Inc: Rockville, MD, 2016.

6. <1094> Capsules-Dissolution Testing and Related Quality Attributes. In The United States Pharmacopeia and National Formulary USP 39-NF 34; The United States Pharmacopeial Convention, Inc: Rockville, MD, 2016.

7. Almukainzi, M.; Salehi, M.; Bou-Chacra, N. A.; Löbenberg, R. Comparison of the Rupture and Disintegration Tests for SoftShell Capsules. Dissolution Technol. 2011, 18 (1), 21-25. DOI: 10.14227/DT180111P21.

8. Gray, V. A.; Cole, E.; Riva Toma, J. M. D.; Ghidorsi, L.; Guo, J.H.; Han, J.-H.; Han, F.; Hosty, C. T.; Kochling, J. D.; Kraemer, J.; Langdon, T.; Leinbach, S. R.; Martin, G. P.; Meyerhoffer, S. M.; Moreton, R. C.; Raghavan, K. S.; Shneyvas, E.; Suggett, J. A.; Tindal, S.; Vadathala, M.; Wang, H.; Anand, O.; Gao, Z.; Shah, R.; Xia, L.; Fotso, J.; Hussain, M. A.; Schmidt, V. N.; Ghosh, T.; Davydova, N.; Brown, W. E.; Fringer, J. M.; Stippler, E. S.; Eranui, T.; Marques, M. R. C. Use of Enzymes in the Dissolution Testing of Gelatin Capsules and Gelatin-Coated Tablets-Revisions to Dissolution $<711>$ and Disintegration and Dissolution of Dietary Supplements <2040>. Dissolution Technol. 2014, 21 (4), 6-19. DOI: 10.14227/DT210414P6.

9. Marques, M. R. C. Enzymes in the Dissolution Testing of Gelatin Capsules. AAPS PharmSciTech 2014, 15 (6), 1410-1416. DOI: 10.1208/s12249-014-0162-3.

10. Brown, J.; Madit, N.; Cole, E. T.; Wilding, I. R.; Cadé, D. The Effect of Cross-Linking on the In Vivo Disintegration of Hard Gelatin Capsules. Pharm. Res. 1998, 15 (7), 1026-1030. DOI: 10.1023/A:1011973909815.

11. Digenis, G. A.; Gold, T. B.; Shah, V. P. Cross-Linking of Gelatin Capsules and Its Relevance to Their in Vitro-in Vivo Performance. J. Pharm. Sci. 1994, 83 (7), 915-921. DOI: 10.1002/ jps.2600830702.

12. Digenis, G. A.; Sandefer, E. P.; Page, R. C.; Doll, W. J.; Gold, T. B.; Darwazeh, N. B. Bioequivalence Study of Stressed and Nonstressed Hard Gelatin Capsules Using Amoxicillin as a Drug Marker and Gamma Scintigraphy to Confirm Time and GI Location of In Vivo Capsule Rupture. Pharm. Res. 2000, 17 (5), 572-582. DOI: 10.1023/A:1007568900147.

13. Meyer, M. C.; Straughn, A. B.; Mhatre, R. M.; Hussain, A.; Shah, V. P.; Bottom, C. B.; Cole, E. T.; Lesko, L. L.; Mallinowski, H.; Williams, R. L. The Effect of Gelatin Cross-Linking on the Bioequivalence of Hard and Soft Gelatin Acetaminophen Capsules. Pharm. Res. 2000, 17 (8), 962-966. DOI: 1023/A:1007579221726. 